\title{
La Sociedad Mexicana de Neumología y Cirugía de Tórax: de un gran pasado a un mejor futuro
}

\author{
Juan Carlos Vázquez-García \\ Presidente de la Sociedad Mexicana de Neumología y Cirugía de Tórax, A.C., 2015-2017. Director de Enseñanza, \\ Instituto Nacional de Enfermedades Respiratorias Ismael Cosío Villegas. Profesor Titular de Neumología, UNAM. \\ Trabajo recibido: 17-V-2017; aceptado: 17-V-2017
}

\begin{abstract}
RESUMEN. La Sociedad Mexicana de Neumología y Cirugía de Tórax fue fundada el 15 de marzo de 1939 con el nombre de Sociedad Mexicana de Estudios sobre la Tuberculosis y Enfermedades del Aparato Respiratorio. Sus objetivos originales eran el estudio de la tuberculosis y las enfermedades pulmonares no tuberculosas, así como la cooperación con organizaciones nacionales y extranjeras de lucha común. Durante sus casi ocho décadas de existencia, ha sido liderada por 39 presidentes y mesas directivas y se ha mantenido como una asociación líder con presencia nacional e internacional. Desde el año de su fundación ha editado ininterrumpidamente su órgano oficial, la revista Neumología y Cirugía de Tórax, NCT, inicialmente la Revista Mexicana de Tuberculosis. Su primer congreso fue el I Congreso Nacional de Tuberculosis y Silicosis, celebrado en el antiguo Instituto de Cardiología, en la Ciudad de México del 23 al 29 de julio de 1944. El congreso de la Sociedad es la mayor manifestación académica de sus especialidades y su historia de 76 congresos testifican su desarrollo y crecimiento. En el año 2016, en el seno de la Asamblea de la Sociedad se aprobaron reformas estatutarias que representan una mayor institucionalización. Sus asociados, así como su estructura actual, científica, profesional y corporativa, son sus mayores fortalezas que la hacen de clase mundial y a la altura de su legado histórico; además, le aseguran un mejor futuro acorde a su misión y visión.
\end{abstract}

Palabras clave: Sociedades profesionales, medicina respiratoria, neumología, cirugía de tórax.

ABSTRACT. The Mexican Respiratory Society of Pulmonary Medicine and Thoracic Surgery, SMNyCT, was instituted on March 15 th, 1939. The original name was Mexican Society of Tuberculosis and Respiratory Diseases and its foundational aims were the study of tuberculosis and respiratory disease and the professional collaboration with national and international common organizations. Under the leadership of 39 presidencies and throughout almost 80 years of existence, it has been an outstanding society with national and international presence and collaboration. The journal Neumología y Cirugía de Tórax or NCT, formerly Revista Mexicana de Tuberculosis, the official publication of the Society, has been continually edited since 1939. The first congress, I National Congress of Tuberculosis and Silicosis was carried out in Mexico City, on July 23-29, 1944. Currently, a total of 76 congresses have been organized and it is one of the greatest meetings in respiratory medicine in the Spanish speaking countries. In the year 2016, major official changes in the constitution of the Society were approved by its General Assembly. Certainly, members of our society and its organizational structure, professional and scientific, ensure a world-class society that honors its history and guarantee our vision and mission.

Key words: Professional societies, respiratory medicine, pulmonologist, thoracic surgery.

\section{LOS ORÍGENES DE LA SMNYCT}

En todo el mundo la Neumología y la Cirugía de Tórax, como especialidades, así como muchas de sus asociaciones profesionales se deben a la tuberculosis. Nuestras especialidades y la Sociedad Mexicana de Neumología y Cirugía de Tórax, A.C. (SMNyCT), no fueron la excepción. La tuberculosis ha acompañado al ser humano en toda su historia. ${ }^{1-5}$ Existen evidencias de fósiles homínidos con lesiones tuberculosas provenientes de hace unos 500 mil años causadas por antiguas bacterias progenitoras, que podrían haberse originado hace más de tres millones de años. ${ }^{2}$ El grupo de bacterias del complejo $M$. tuberculosis causantes de la enfermedad en el humano moderno, no datan de hace más de 40 mil años y han acompañado a la humanidad desde su origen en África y, desde ahí, en su proceso de migración hacia el resto de los continentes. ${ }^{5}$ Algunos de los nombres con los que se conoció en las civilizaciones antiguas fueron phtysis en Grecia, sosha (India), consumptione (Latina) y chaky onkay (Inca); todos ellos significan secar o consumir, como una referencia al comportamiento y evolución crónica de la enfermedad. En la historia de la tuberculosis destaca el siglo XIX por 
su diseminación epidémica y los grandes avances en el conocimiento de la enfermedad; todavía conocida como consunción, fue también bautizada como la epidemia blanca. En este período, Jean-Antoine Villemin (1865) en Francia demostró su naturaleza contagiosa y, más tarde, el médico, bacteriólogo y científico alemán Roberto Koch (1882) descubrió el bacilo tuberculoso.

Los primeros sanatorios para personas con tuberculosis datan de la primera mitad del siglo XIX. Históricamente, como primer sanatorio para enfermos de tuberculosis se reconoce al Sanatorio de Görbersdorf, Silesia, actualmente, Polonia, construido en 1847 a 650 metros sobre el nivel del mar por el médico Hermann Brehmer con ayuda de Alexander Von Humboldt. En 1884, Edward Livingston Trudeau quien sufría de tuberculosis fundó el primer sanatorio de tuberculosis en América, en el Lago Saranac, Nueva York. En América Latina, el primer sanatorio se fundó en Mar del Plata, Argentina, en 1893. El Hospital General de México, cuna de las especialidades y de los Institutos Nacionales de Salud en nuestro país, se inauguró en 1905 y desde sus inicios es el primer nosocomio en contar con pabellones específicos para personas con tuberculosis. ${ }^{6}$ Sin embargo, se recuerdan más como una especie de repositorios de enfermos avanzados, más que servicios médicos; la comida, la ropa y los medicamentos eran escasos y los médicos se rehusaban a visitar a los enfermos. ${ }^{7}$ En 1927, el primer médico en organizar la atención de estos pacientes fue Ismael Cosío Villegas (1902-1985) quien se convirtió en jefe de los tres pabellones de tuberculosis. ${ }^{7}$ El Dr. Donato G Alarcón (1899-1991) se incorporó al Hospital General de México en 1933, posterior a completar su formación especializada en tuberculosis en Estados Unidos gracias a la beca Guggenheim. 7,8

En 1929, durante la presidencia de Emilio Portes Gil y siendo jefe del Departamento de Salubridad Pública el Dr. Aquilino Villanueva, se inició la Campaña Antituberculosa como una política de servicio público, organizada y sostenida permanentemente por el Estado. La dirección técnica fue encargada al Dr. Ismael Cosío Villegas. En diciembre de este mismo año, la H. Cámara de Diputados estableció en el presupuesto de Salubridad Pública la dotación necesaria para la construcción del Sanatorio para Enfermos de Tuberculosis de Huipulco.9,10 Desde 1930, Ismael Cosío Villegas y su amigo el Arq. José Barragán, autor del proyecto, planean y presionan políticamente su construcción que tomó más de cinco años. En 1935, el proyecto fue directamente encomendado al Dr. Donato G Alarcón quien revisó y actualizó los planos y supervisó la conclusión del mismo; inaugurado el 31 de diciembre de 1935, el Dr. Alarcón fue nombrado su primer director. El Sanatorio de Huipulco hoy Instituto Nacional de Enfermedades Respiratorias Ismael Cosío Villegas celebró sus primeros 80 años de vida el 16 de marzo de 2016, fecha establecida en honor al aniversario del ingreso de sus primeros pacientes. ${ }^{11}$

\section{LA FUNDACIÓN DE LA SMNYCT}

En 1937, tan sólo un año después de ser fundado el Sanatorio de Huipulco, un grupo de médicos tisiólogos se reunía en la Ciudad de México para charlar sobre problemas médicos relacionados con la tuberculosis pulmonar. ${ }^{12}$ Entre ellos estaban los doctores Donato G Alarcón, Ismael Cosío Villegas, Alejandro Celis Salazar, Miguel Jiménez Sánchez, Aniceto del Río y Fernando Rébora Gutiérrez. Este grupo selecto se autonombró «Los Amigos del Bacilo de Koch». El 15 de marzo de 1939 reunidos en el Sanatorio de Huipulco, se funda oficialmente la Sociedad Mexicana de Estudios sobre la Tuberculosis y Enfermedades del Aparato Respiratorio, con los fines: 1) el estudio de la tuberculosis y las enfermedades pulmonares no tuberculosas; y 2) cooperación con organizaciones de lucha antituberculosis del país y del extranjero para la campaña contra la enfermedad. ${ }^{2}$ En el acta aparece un total de 27 miembros (figura 1) encabezados por los doctores Donato G Alarcón e Ismael Cosío Villegas. ${ }^{13}$

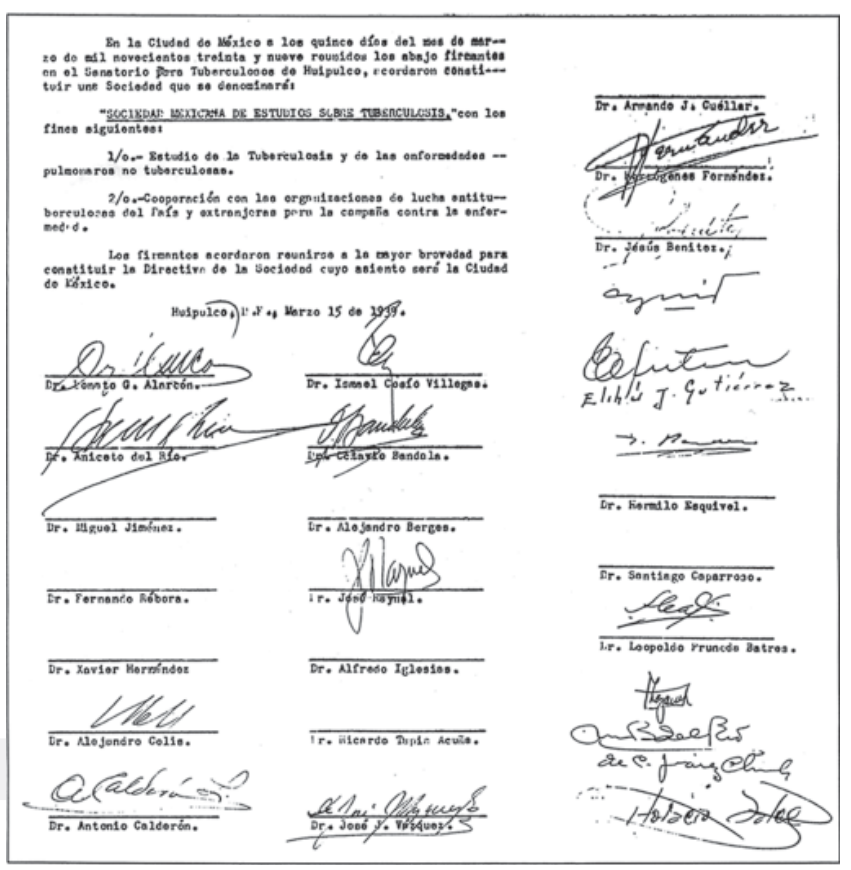

Figura 1. Acta fundacional de la Sociedad Mexicana de Estudios sobre la Tuberculosis y Enfermedades del Aparato Respiratorio, ahora, Sociedad Mexicana de Neumología y Cirugía de Tórax, A.C., fechada en Huipulco, Ciudad de México, el 15 de marzo de 1939. 
El jueves 4 de mayo de 1939 se celebró la segunda reunión oficial de la naciente sociedad en el aula Miguel Jiménez de la Escuela de Medicina. En esta reunión el Dr. Alarcón aparece ya como primer Presidente de la Sociedad y se propone hacer un estudio de investigación de infección tuberculosa en estudiantes de medicina; para ello, planean un estudio radiológico y de tuberculina en todos los estudiantes de primer y segundo año de la carrera. Durante los primeros seis meses, de julio a diciembre de 1939 , se organizaron 14 sesiones científicas donde se presentaron trabajos leídos por distinguidos miembros, además, resaltan los doctores Reynaldo Gómez, Gustavo Bergnes y José Luis Guerra del Sanatorio Esperanza de La Habana, Cuba. ${ }^{14}$ Algunas disertaciones fueron: Broncoscopia directa en las tuberculosis pulmonares, resultado de 50 casos, Dr. Ricardo Tapia; El tratamiento quirúrgico de la tuberculosis pulmonar, resultados de 736 operaciones por el Dr. Donato Alarcón; Algunos aspectos clínicos de los síndromes de supuración pulmonar, Dr. Ismael Cosío Villegas; Acerca del diagnóstico radiológico del cáncer pulmonar por los Dres. Octavio Bandala y Alejandro Celis. Todos estos trabajos fueron posteriormente publicados formalmente en la revista de la Sociedad.

\section{EL NACIMIENTO DE LA REVISTA NCT}

En la misma primera sesión reglamentaria de la sociedad del día 4 de mayo de 1939, el Dr. Alarcón pidió autorización para que la mesa directiva realizara los pasos necesarios para que se publicara el primer número de una revista, órgano oficial de la Sociedad. ${ }^{13}$ Esta noción es aprobada junto con una propuesta adicional del Dr. Celis, de que todos los trabajos publicados por la revista fueran primero leídos en las sesiones reglamentarias. En la sesión del 6 de julio del mismo año, el Dr. Alarcón presentó un presupuesto de $\$ 500.00$ para la impresión de mil ejemplares. Asimismo, se aprueba que el costo fuera cubierto con las cuotas de los socios de la Ciudad de México. En la sesión del 10 de agosto de 1939, el Dr. Alarcón informó que el Dr. Gustavo Baz, Rector de la Universidad, autorizó la impresión de la revista en la imprenta de la Universidad, pero que el costo del papel y de los clichés debería ser cubierto por la Sociedad. En la sesión reglamentaria del 5 de octubre de 1939, el Dr. Alarcón presentó oficialmente el primer número de la Revista Mexicana de Tuberculosis y Enfermedades del Aparato Respiratorio (figura 2), hoy revista de Neumología y Cirugía de Tórax o NCT. Este primer número cubría el período de julio a agosto de 1939 y funge como director el Dr. Alarcón. En este primer número aparecen 38 miembros numerarios de la sociedad, de los cuales 22 eran de la Ciudad de México y 16 de los estados. Además, se incluyen 4 miembros correspondientes residentes de La Habana, Cuba. En el año 2010, el Dr. Andrés Palomar, Presidente de la SMNyCT y el Dr. Rogelio Pérez Padilla, Director del INER, firman un acuerdo para la fusión de las revistas Neumología y Cirugía de Tórax

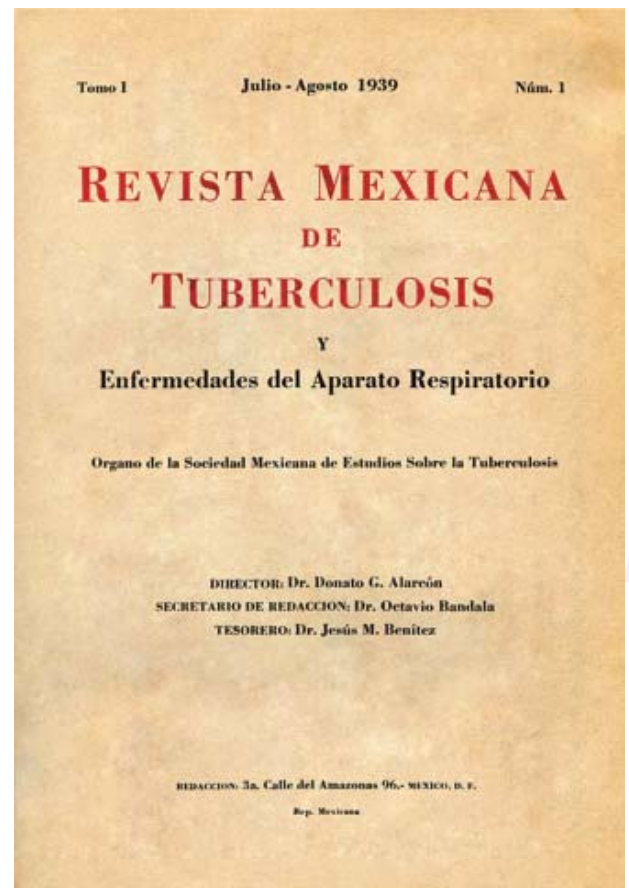

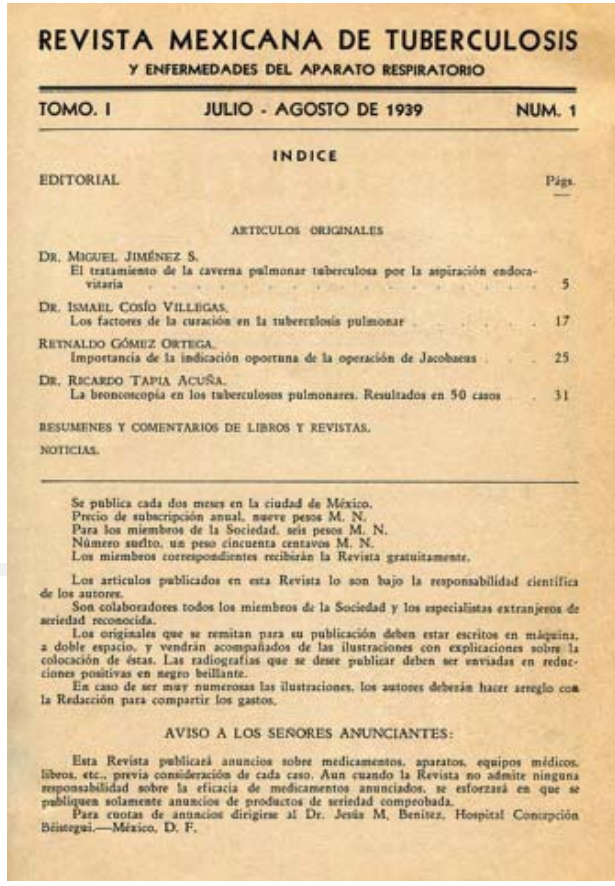

\section{Figura 2.}

Portada e índice del primer número de la Revista Mexicana de Tuberculosis presentada por el Dr. Donato G Alarcón en sesión de la Sociedad Mexicana de Estudios de Tuberculosis el 5 de octubre de 1939; actualmente, Neumología y Cirugía de Tórax, NCT. 
y la Revista del INER, mismo que fue aprobado por la Asamblea General del mismo año; es como nace NCT.

En 1939 México tenía poco más de 19 millones de habitantes, el General Lázaro Cárdenas, presidente de la república, estaba en su último año de gestión y corría el proceso de sucesión presidencial en medio de una situación de inflación y carestía. En Europa comenzaba la Segunda Guerra Mundial y nuestro país recibía 20 mil refugiados provenientes de Francia, principalmente españoles republicanos. La esperanza de vida era apenas poco mayor de 40 años y la tuberculosis pulmonar era la séptima causa de muerte general; anualmente, morían 13 mil personas de tuberculosis, más de 10 mil en su forma pulmonar y se estimaba que el número de enfermos podría ser 10 veces la cifra de muertos. ${ }^{14}$

\section{CAPÍTULO MEXICANO DEL ACCP}

Desde sus orígenes la SMNyCT tuvo una relación directa con sociedades hermanas internacionales. En septiembre de 1943 se fundó en la Ciudad de México, el Capítulo Mexicano del American College of Chest Physicians (ACCP) de los Estados Unidos. Lo constituyeron un total de 19 miembros fundadores, de los cuales asistieron 12 a la ceremonia inaugural con la presencia del Dr. Edgar Mayer representante oficial de la ACCP (figura 3 ). ${ }^{15}$

\section{CONGRESO NACIONAL DE TUBERCULOSIS Y SILICOSIS}

El primer congreso de la Sociedad fue el I Congreso Nacional de Tuberculosis y Silicosis que se celebró

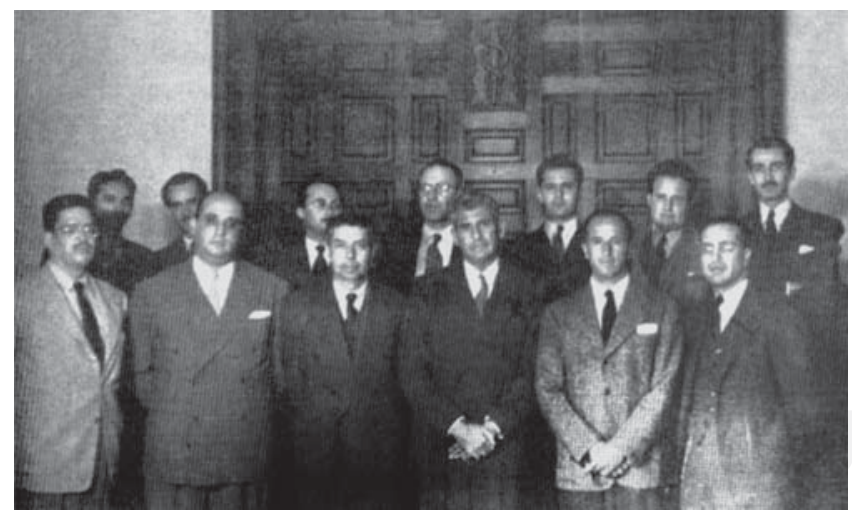

Figura 3. Constitución del Capítulo Mexicano del American College of Chest Physicians (ACCP) en 1943. El Dr. Edgar Mayer (tercero desde la derecha) acudió en representación de la ACCP, está flanqueado a su derecha por el Dr. Donato G Alarcón y el Dr. Miguel Jiménez y a su izquierda el Dr. Ismael Cosío Villegas. del 23 al 29 de julio de 1944 con sede en el Instituto de Cardiología, localizado en la esquina de la Calzada de la Piedad y Dr. Márquez (figuras 4 y 5). El Presidente de la Sociedad era el Dr. Miguel Jiménez Sánchez y también fungió como Presidente Ejecutivo del congreso, mientras que el Presidente Honorario fue el Dr. Gustavo Baz, Secretario de Salubridad y Asistencia. ${ }^{16}$ Contrario a la expectativa inicial de organizar un evento pequeño de orden local, se logró un magno evento de gran relevancia nacional e internacional. Se presentó un total de 451 asistentes; destacaron, una delegación de Cuba de seis médicos, el Dr. Aresky Amorin, prestigiado cirujano de Brasil; Gumersindo Sáyago, fundador de la escuela de Tisiología de Córdoba, Argentina; de los Estados Unidos se presentaron el Dr. Leo Eloesser, Julius L Wilson y Herman E Hilleboe, Low y George G. Ornstein, Director del Instituto Neumológico de Nueva York.

En este I Congreso se presentaron 121 trabajos, la gran mayoría sobre tuberculosis, entre ellos el Dr. Donato Alarcón dictó la conferencia Resultados de toracoplastia, donde informó de 605 toracoplastias en 328 enfermos; el Dr. Cosío Villegas presentó la conferencia Síndromes de supuración pulmonar y los Dres. Julián González Méndez, Alfonso Estrada y Alejandro Celis, del Hospital General, presentaron su trabajo sobre resecciones pulmonares que incluía 65 lobectomías y 10 neumonectomías, dos de ellas en pacientes con tuberculosis pulmonar. La mayoría de los trabajos del congreso fueron publicados en un documento de más de 600 páginas (figura 6$)^{16}$

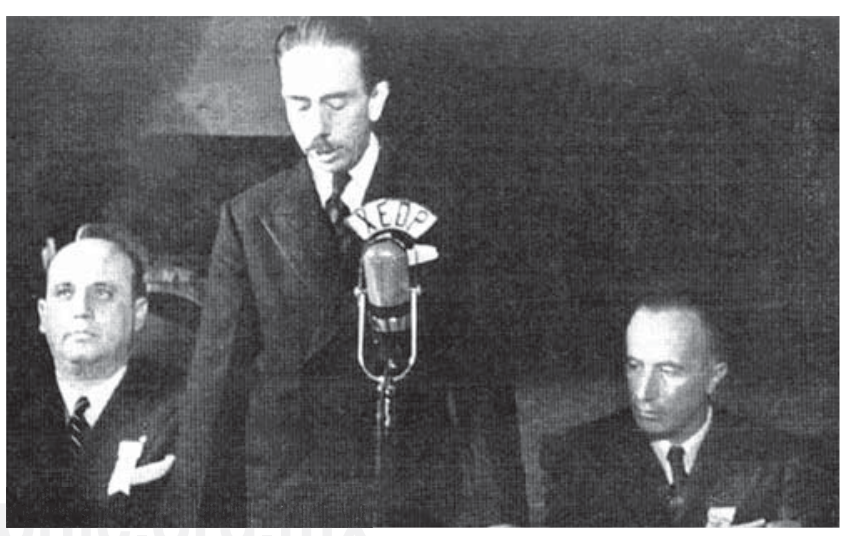

Figura 4. Ceremonia inaugural del I Congreso Nacional de Tuberculosis y Silicosis (23 al 29 de julio de 1944), encabezada por el Dr. Gustavo Baz (al micrófono), Presidente Honorario del Congreso, Dr. Miguel Jiménez (izquierda), Presidente de la Sociedad Mexicana de Estudios sobre la Tuberculosis y Presidente Ejecutivo del Congreso y el Dr. Ismael Cosío Villegas (derecha), Director del Comité Nacional de Lucha contra la Tuberculosis. 


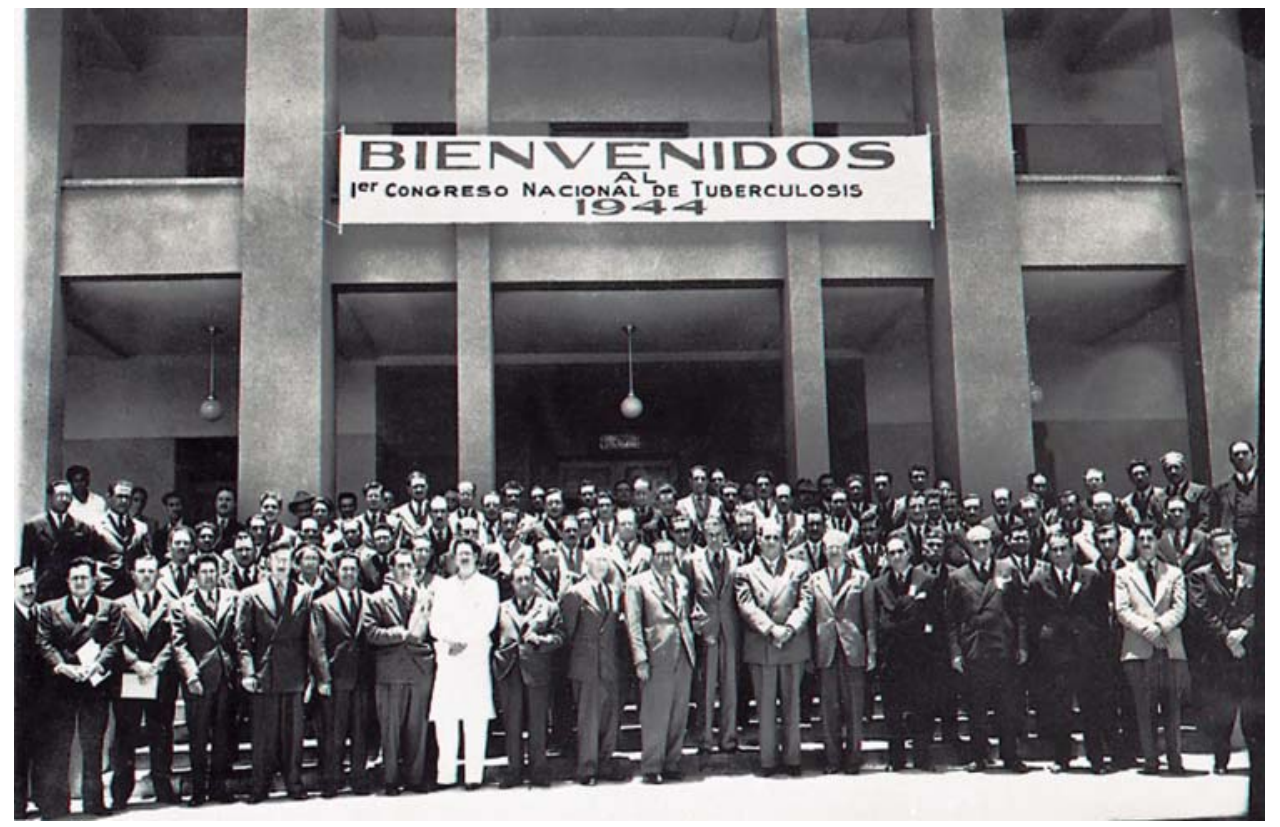

Figura 5.

Participantes del I Congreso Nacional de Tuberculosis y Silicosis de la Sociedad Mexicana de Estudios sobre la Tuberculosis y Enfermedades del Aparato Respiratorio hoy Sociedad Mexicana de Neumología y Cirugía de Tórax, celebrado en el antiguo Instituto Nacional de Cardiología del 23 al 29 de julio de 1944.
SOCIEDAD MEXICANA DE ESTUDIOS SOBRE TUBERCULOSIS Y ENFERMEDADES DEL APARATO RESPIRATORIO

\section{ESTUDIOS \\ SOBRE}

TUBERCULOSIS Y SILICOSIS

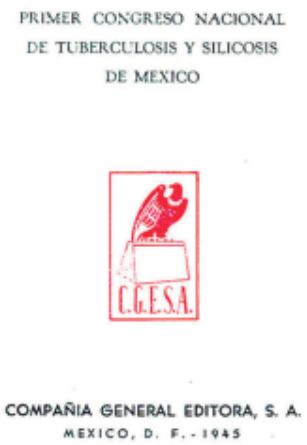

COMPANIA GENERAL EDITORA, S. A.$$
\text { MEXICO, D. F.. 1945 }
$$

Figura 6. Portada de las memorias del I Congreso Nacional de Tuberculosis y Silicosis. Este documento de más de 600 páginas compila la mayoría de las disertaciones y sus comentarios oficiales presentados durante el I congreso.

Durante la sesión de clausura del congreso, el Dr. Ismael Cosío Villegas encabezó por parte del Comité de Lucha contra la Tuberculosis un homenaje al Dr. Manuel Gea González, debido a que uno de los hospitales en construcción llevará su nombre. Asimismo, el Comité brinda la cena de clausura del congreso que se celebró en el Casino Español con más de mil asistentes.

\section{LA EVOLUCIÓN}

Los primeros cinco presidentes de la sociedad fueron el Donato G Alarcón (1939-1941), Ismael Cosío Villegas (1941-1943), Miguel Jiménez (1943-1945), Fernando Rébora Gutiérrez (1945-1947) y Alejandro Celis Salazar (1947-1949). EI Tercer Congreso Nacional se realizó bajo la Presidencia del Dr. Alejandro Celis Salazar del 23 al 29 de enero de 1949, en el Instituto de Cardiología de la Ciudad de México; fue organizado simultáneamente con el VIII Congreso de la Unión Latinoamericana de Sociedades de Tuberculosis (ULAST), por lo que resultó el primer congreso de la sociedad con gran presencia internacional, especialmente de los Estados Unidos. ${ }^{17}$ La Revista Mexicana de Tuberculosis pasó a ser Neumología y Cirugía de Tórax desde su primer número del año 1962 (figura 7) y la Asamblea General de la Sociedad reunida el 16 de agosto de ese mismo año, durante la presidencia del Dr. José Ramírez Gama, aprueba por unanimidad que el organismo se denomine Sociedad Mexicana de Neumología y Cirugía de Tórax, SMNyCT (figura 7). ${ }^{18}$ El Dr. Octavio Rivero Serrano fue Presidente durante el bienio 1965-1966. El Dr. Raúl Cicero Sabido fue décimo quinto presidente y llevó a cabo la Séptima Reunión Nacional en Acapulco, Guerrero, en octubre de 1966; asimismo, organizó el XIII Congreso Nacional en conjunto con el XVI Congreso de la ULAST en la Unidad de Congresos del Centro Médico Nacional, en 

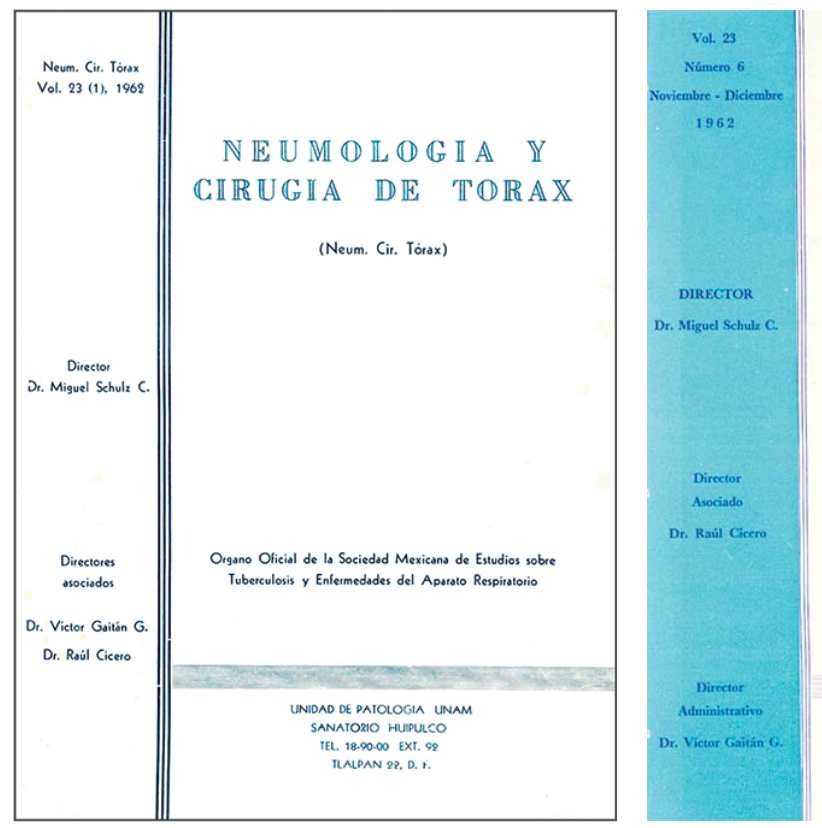

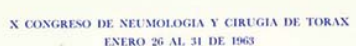

NE U M O L O G I A Y CIRUGIA DE TORAX

(Neum. Cir: Tórax)

ORGANO OFICALL DE LA SOCHEDAD MEXICANA DE NETHOLOGIA Y CIRTGIA DE TORAX

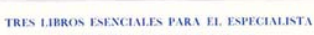
Ex พTIOLOGIL, YER PMG. II

\section{Figura 7.}

Portada de la revista que corresponde al primer número de 1962 (volumen 29, número 1), donde aparece por primera vez con el nombre de Neumología y Cirugía de Tórax, órgano oficial de la todavía Sociedad Mexicana de Estudios sobre Tuberculosis (izquierda). La otra portada (derecha) corresponde al número 6 del mismo año, donde ya aparece como órgano oficial de la Sociedad Mexicana de Neumología y Cirugía de Tórax. la Ciudad de México, del 13 al 18 de abril de 1969; el Dr. Miguel Jiménez fue presidente del congreso por parte de la ULAST. EI Dr. Horacio Rubio Monteverde organizó el XX Congreso Nacional de Neumología y Cirugía de Tórax en Ixtapan de la Sal, del 23 al 26 de marzo de 1983, donde se presentó por primera vez el tema: Patología pulmonar experimental, presentada por los doctores Moisés Selman Lama y Ruy Pérez Tamayo. En 1982, realizó la XXI Reunión Nacional de la Sociedad en conjunto con el Congreso Internacional en Celebración del Centenario del Descubrimiento del Bacilo de la Tuberculosis. La Dra. María Elisa Celis Barragán fue la primera mujer presidente (1983-1985). En 1988, durante la presidencia el Dr. Carlos Ibarra Pérez se participó con la fusión-concordancia de congresos; las XIX Jornadas Médicas del INER, la XXV Reunión de la Sociedad y el XXIII Congreso Panamericano de la ULAST, la cual estaba bajo la presidencia del Dr. Rubio Monteverde. El Dr. Ibarra también organizó el XXIII Congreso Nacional en el marco del cincuentenario de la Sociedad (figura 8) en la Unidad de Congresos del Centro Médico Nacional el 6 al 11 de marzo de $1989 .{ }^{19}$

El Dr. Moisés Selman Lama, Director de Investigación del INER y Premio Nacional de Ciencias, fue Presidente durante el bienio 1991-1993; organizó el II Congreso Iberoamericano de Neumología del 8 al 13 de junio de 1992 (figura 8), reuniendo a destacados líderes internacionales de la medicina respiratoria, quienes posteriormente fundarían la Asociación Latinoamericana de Tórax (ALAT). El Dr. Manuel Díaz González, fundador de los servicios y especialidades de Neumología y Terapia Intensiva del Hospital Universitario de Nuevo León, fue el primer presidente de la Sociedad fuera de la Ciudad de México. En el marco del LX aniversario de la Sociedad se celebró el LVIII Congreso en la Ciudad de Veracruz, bajo la presidencia del Dr. León Green; en este congreso se presentaron y publicaron un total de 84 trabajos libres (NCT 1999; 58, supl.). La Dra. Rocío Chapela Mendoza fue la segunda mujer Presidente de la SMNyCT (2001-2003) y organizó el LXI Congreso en Mazatlán en 2003 y el LXII Congreso en Puerto Vallarta en 2004. Correspondió al Dr. José Felipe Villegas Elizondo, también del Hospital Universitario de Monterrey, organizar el LXV Congreso de nuestra sociedad en conjunto con el V Congreso ALAT del 3 al 7 de julio de 2006 en Cancún, Quintana Roo, México.

Recientemente, durante el bienio 2010-2011, la mesa directiva a cargo del Dr. Andrés Palomar Lever implementó las Divisiones Numerarias de la Sociedad que incluyen Neumología, Neumopediatría y Cirugía Tórax, así como la División de Enfermería y de Técnicos Respiratorios. Además, establecieron convenios de colaboración oficial con la ALAT, la Sociedad Española de Neumología y Cirugía Torácica (SEPAR) y la Asociación Argentina de Medicina Respiratoria (AAMR), permitiendo el intercambio formal de profesores y becarios. Los congresos de este período correspondiente al LXX Congreso en Guadalajara (2010) y LXXI Congreso en Puebla (2011), por primera vez, convocaron una gran afluencia de congresistas y profesores extranjeros. 


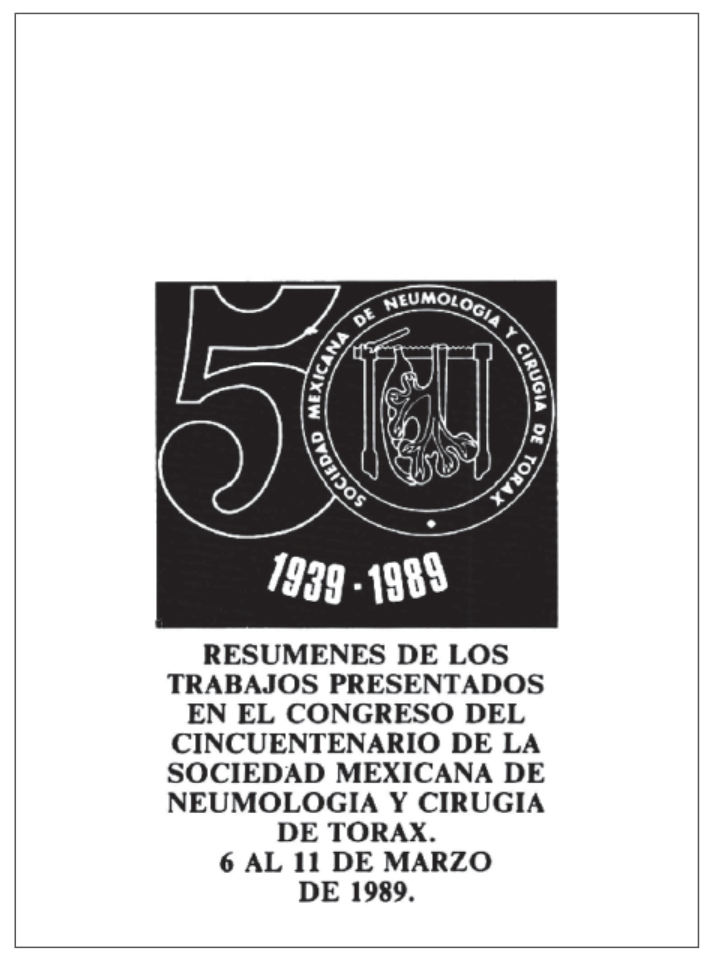

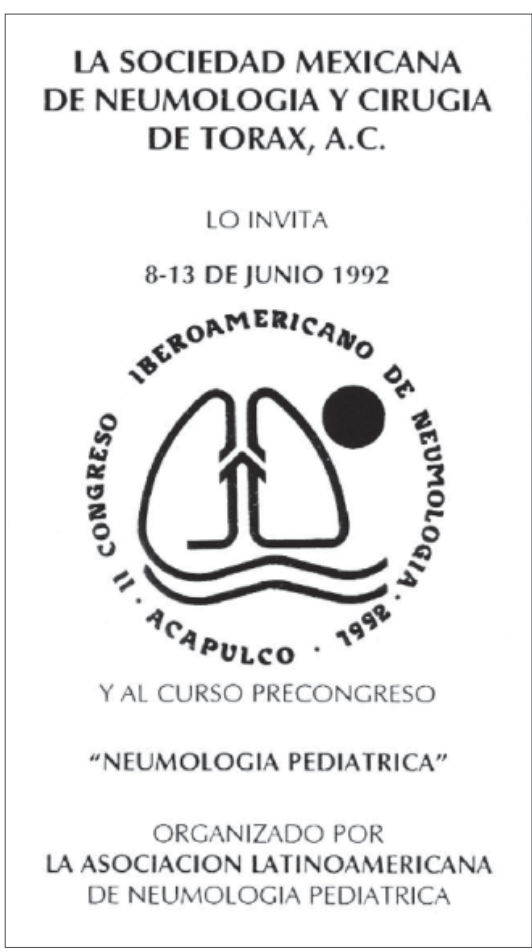

Figura 8.

A la izquierda, la portada de publicación de trabajos presentados en el congreso del cincuentenario de la Sociedad. La imagen de la derecha corresponde al cartel promocional del II Congreso Iberoamericano de Neumología en 1992.

\section{UNA SMNYCT MODERNA DE CLASE MUNDIAL Y PRESENCIA INTERNACIONAL}

Desde su fundación, hace 78 años, y bajo el liderazgo de 39 presidentes la SMNyCT ha celebrado un total de 76 congresos científicos. El congreso de la Sociedad ha sido siempre la mayor manifestación académica de nuestras especialidades en México. Actualmente, es un evento académico de clase mundial y una referencia para los especialistas del mundo de habla hispana. Un logro que nos distingue es haberlo mantenido en un ambiente de unión fraternal entre sus socios e incluso sus familias. Del 28 de marzo al $1^{\circ}$ de abril de 2016 celebró su congreso de aniversario; 75 Congreso Diamante (figura 9) y el pasado mes de abril de 2017, se celebró el 76 Congreso de la Sociedad, Congreso de las Américas, en la Ciudad de Puebla de los Ángeles. ${ }^{20}$ Durante cinco días, un total de 1,630 asistentes (1,057 congresistas) convivieron con 53 profesores extranjeros; se dictaron casi 500 conferencias donde se hizo evidente el alto nivel de la medicina respiratoria y sus altas especializaciones. La SMNyCT es la mayor fuente de actualización y educación continua de los especialistas respiratorios; además, cuenta con programas de apoyo a especialistas en formación, promociona la investigación científica y el combate a las enfermedades respiratorias. ${ }^{20}$

La firma de un convenio de colaboración especial con la ALAT y la Sociedad Europea Respiratoria (ERS), desde el año 2015, permite a los socios contar con una triple membresía bajo el mismo costo y múltiples beneficios. Los convenios internacionales se han ampliado a la Federación Centroamericana y del Caribe de Neumología y Cirugía de Tórax (FCCNCT) y a la Sociedad de Enfermedades Respiratorias de Chile (SERChile). Las redes de trabajo nacionales e internacionales, sin duda, son un referente de buena colaboración, acercamiento y lucha común.

\section{UNA SMNYCT MÁS INSTITUCIONAL Y CORPORATIVA}

El crecimiento natural de la SMNyCT así como la presencia nacional e internacional, la han obligado a evolucionar en una asociación más institucional y con un cuerpo de gobierno profesional y corporativo, lo que garantiza un trabajo más eficiente para su creciente complejidad. Durante la Asamblea General legalmente instalada el 31 de marzo de 2016, se aprobó una serie de reformas que representan un cambio mayor en la institucionalización de la sociedad. Estas reformas incluyen: 1) la creación de un Comité Ejecutivo compuesto por el Presidente, Vicepresidente, Presidente Pasado, Secretario, Tesorero, Jefes de las Divisiones de Neumología, Neumopediatría y Cirugía de Tórax, así como la integración de un Comisario; 2) se creó la figura de un Comisario Fiscal quien fue elegido directamente por la Asamblea, con una duración indefinida y quien es responsable de la 
aprobación anual de las cuentas y estados financieros de la Sociedad; 3) se aprobó la creación de un Comité de Investigación y Educación responsable de la gestión, promoción y operación de las actividades propias de educación continua y de investigación; 4) creación de grupos científicos o Departamentos de la División de Neumología que deberán proponer un plan de trabajo con actividades propias de los congresos, de educación continua, de investigación, generación de normativas y recomendaciones, así como promoción de la salud propia de la materia; y 5) una mayor autonomía y democracia de los capítulos estatales. La reorganización de la Sociedad, con base en un Comité Ejecutivo y una administración profesional con direcciones ejecutiva y administrativa (ya implementadas) y, eventualmente, una de mercadotecnia, consolida un cuerpo de gobierno corporativo a la altura de sus objetivos. En la figura 10 se muestra el nuevo esquema organizacional de la Sociedad.

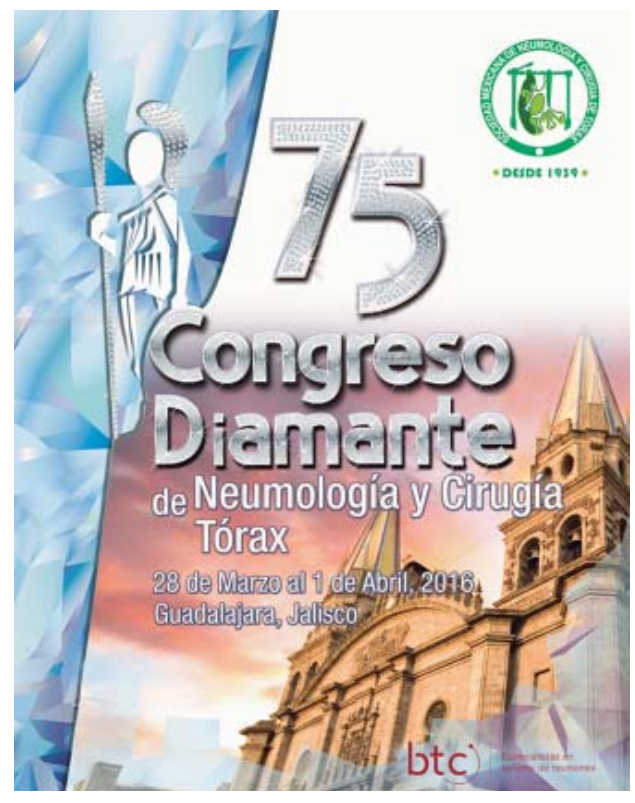

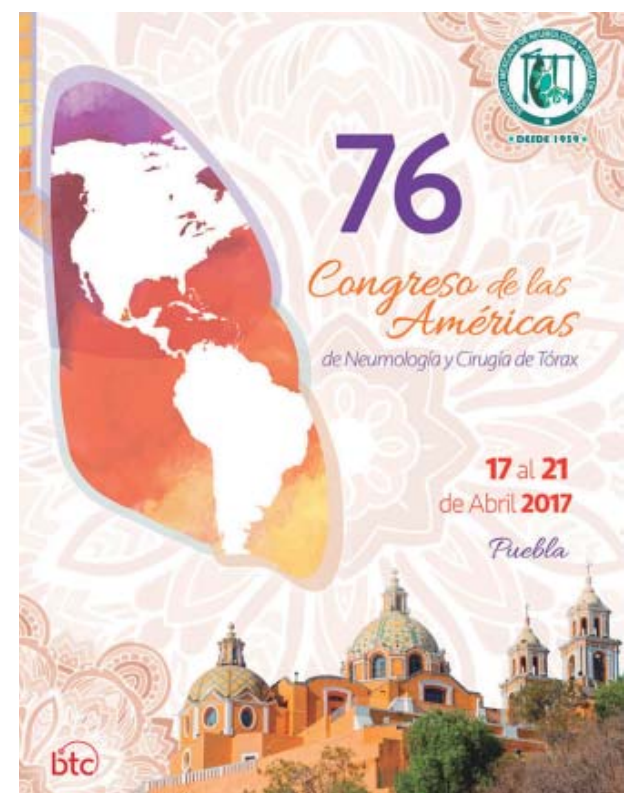

Figura 9.

Carteles promocionales de los congresos de 2016 (75) y 2017 (76) de la Sociedad Mexicana de Neumología y Cirugía de Tórax.

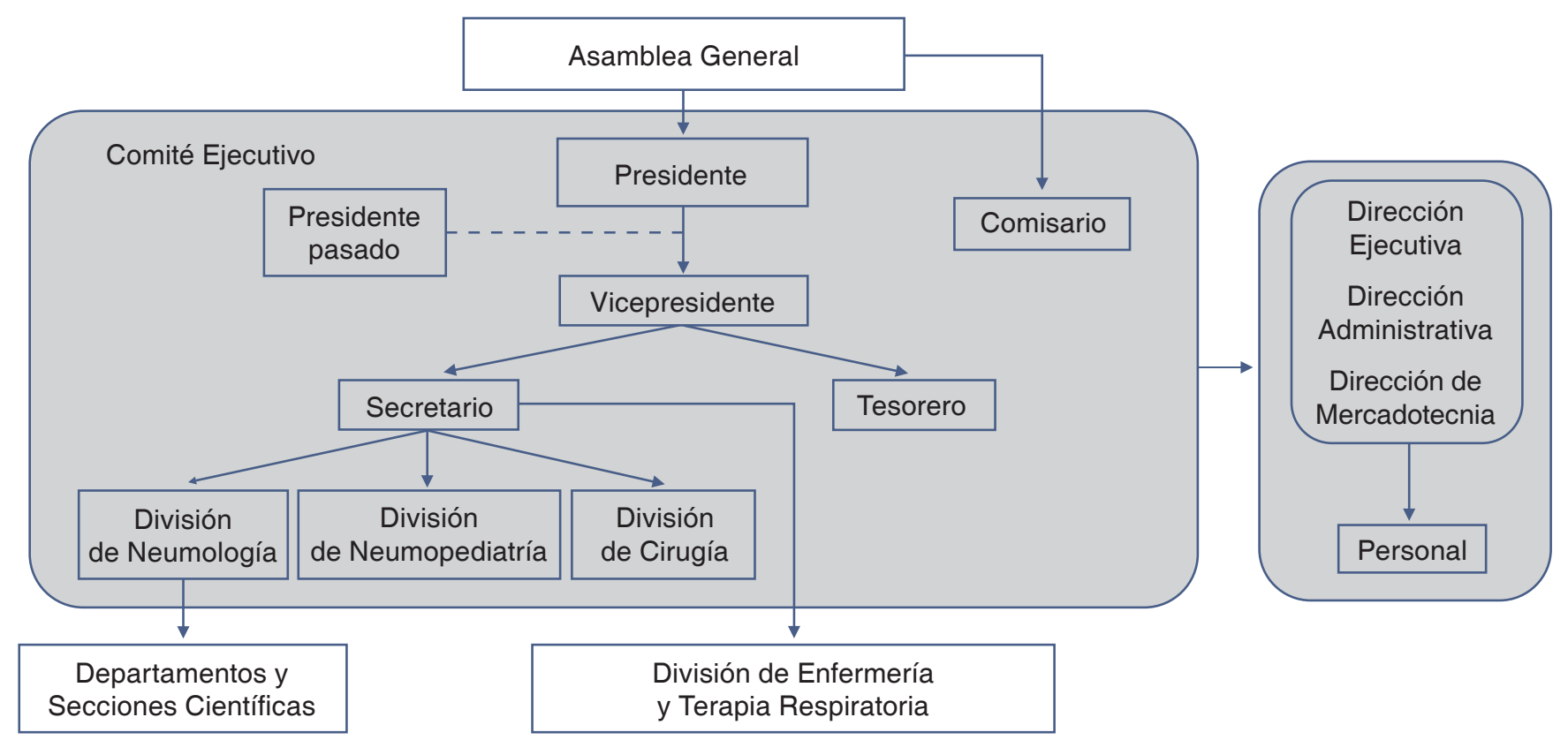

Figura 10. Nuevo esquema organizacional de la Sociedad Mexicana de Neumología y Cirugía de Tórax. 


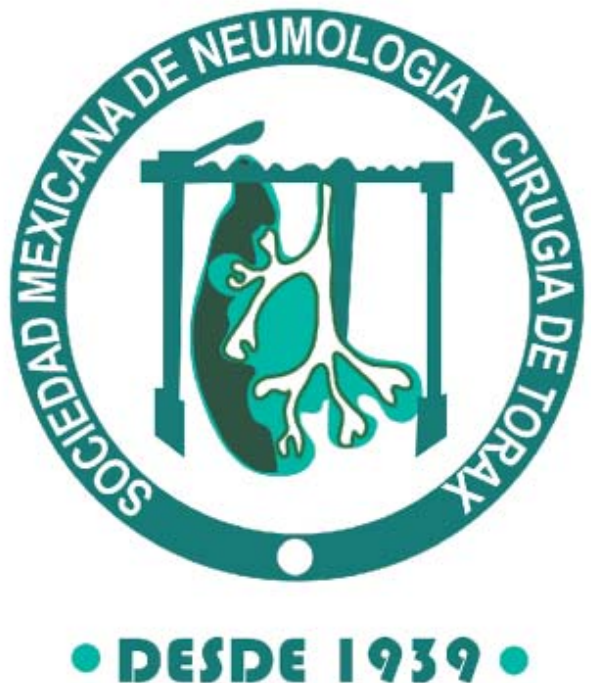

\section{Misión}

La SMNyCT es una asociación civil sin fines de lucro, profesional y científica, que se enfoca en la promoción de la salud respiratoria, así como en la prevención, detección y tratamiento de las enfermedades respiratorias, a través de la educación, la investigación, el cuidado y defensa de los pacientes y la colaboración nacional e internacional con sociedades hermanas de lucha común.

\section{Visión}

Mantenernos como la organización no gubernamental líder de la Medicina Respiratoria en México, para la promoción, educación e investigación relacionada con la salud respiratoria.

\section{Figura 11.}

Visión y Misión de la Sociedad Mexicana de Neumología y Cirugía de Tórax.

\section{LA MISIÓN Y VISIÓN DE LA SMNYCT: SU PRESENTE Y SU FUTURO}

La SMNyCT se acerca a sus primeros 80 años de vida más fortalecida que nunca. Su desarrollo, propio de sus dimensiones y alcances, ha sido complejo y lleno de retos. Sin embargo, ha logrado mantenerse como una Sociedad de gran convocatoria y representación nacional y presencia internacional. Ha evolucionado de una sola especialidad y prácticamente una enfermedad: la tuberculosis, hasta la complejidad de sus tres especialidades actuales, incluso ahora abraza a otras áreas profesionales. Nuestra Asociación está lista para un futuro más grande y sólido que verá crecer a sus afiliados, sus especialidades y altas especialidades que son ya una realidad. Sin duda, el trabajo y la unión de sus socios son la mayor fortaleza para que la SMNyCT cumpla con su Misión y Visión propia de una Asociación líder, de clase mundial y como un referente internacional (figura 11).

\section{REFERENCIAS}

1. Cartes PJC. Breve historia de la tuberculosis. Rev Med Cos Cen 2013;70(605):145-150.

2. Bynum H. Spitting blood. The history of tuberculosis. Oxford University Press, UK; 2012.

3. Brosch R, Gordon SV, Marmiesse M, et al. A new evolutionary scenario for the Mycobacterium tuberculosis complex. Proc Natl Acad Sci U S A 2002;99(6):3684-3689.

4. Gutierrez MC, Brisse S, Brosch R, et al. Ancient origin and gene mosaicism of the progenitor of Mycobacterium tuberculosis. PLoS Pathog 2005;1(1):e5.

5. Wirth T, Hildebrand F, Allix-Béguec C, et al. Origin, spread and demography of the Mycobacterium tuberculosis complex. PLoS Pathog 2008;4(9):e1000160. doi: 10.1371/journal.ppat.1000160.

6. Álvarez CR. La fundación del Hospital General de México. Rev Fac Med UNAM 2010;53(5):23-28.

7. Rivero SO. Los pilares de la neumología en México. Seminario el ejercicio actual de la medicina. Facultad de Medicina, UNAM. Fecha de consulta: 14-VIII-2016. Disponible en: http://www.facmed.unam.mx/sms/ seam2k1/2008/oct_04_ponencia.html.

8. Pérez PJR. El doctor Donato G. Alarcón Martínez, fundador de instituciones dedicadas al estudio de las enfermedades respiratorias. A quince años de su fallecimiento. Gac Med Mex 2006;142(4):345-352.

9. Cárdenas de la PE. Del Sanatorio de Huipulco al Instituto Nacional de Enfermedades Respiratorias. Cincuenta años. México: Secretaría de Salud; 1986.

10. Pérez PR. Instituto Nacional de Enfermedades Respiratorias Ismael Cosío Villegas: 75 años de servicio. Neumol Cir Torax 2010;69(4):191-194.

11. Salas HJ, Olvera ME. Instituto Nacional de Enfermedades Respiratorias Ismael Cosío Villegas. México: Intersistemas; 2017.

12. Rubio MH. Historia de los congresos de la Sociedad Mexicana de Neumología y Cirugía de Tórax. 70 años. México: SMNyCT; 2009.

13. Pérez PJR. Nuestra historia. Neumol Cir Torax 1993;52(3):38-45.

14. Secretaría de Salud. Información histórica de estadísticas vitales. Nacimientos y defunciones 1893-2010. México: SSA; 2011.

15. Sociedad Mexicana de Estudios sobre Tuberculosis y Enfermedades del Aparato Respiratorio. Noticias. Revista Mexicana de Tuberculosis 1943;5(27):193-194.

16. Sociedad Mexicana de Estudios sobre Tuberculosis y Enfermedades del Aparato Respiratorio. Estudios sobre tuberculosis y silicosis. Primer Congreso Nacional de Tuberculosis y Silicosis de México. México, D.F.: Compañía General Editora; 1945. 
17. Sociedad Mexicana de Estudios sobre Tuberculosis y Enfermedades del Aparato Respiratorio. Noticias. Revista Mexicana de Tuberculosis 1949;10(45):62-64.

18. Ramírez GJ. Sociedad Mexicana de Neumología y Cirugía de Tórax (editorial). Neumol Cir Torax 1962;23(5):299-300.

19. Sociedad Mexicana de Estudios Sobre Tuberculosis y Enfermedades del Aparato Respiratorio. Congreso del cincuentenario. Neumol Cir Torax 1989;68(2):36-38.

20. Vázquez GJC. Sociedad Mexicana de Neumología y Cirugía de Tórax, A.C. Informe de Labores de la Mesa Directiva 2015-2017. Neumol Cir Torax 2017;76(2):78-83. $\triangle$ Correspondencia:

Dr. Juan Carlos Vázquez-García

Dirección de Enseñanza,

Instituto Nacional de Enfermedades Respiratorias Ismael Cosío Villegas.

Calzada de Tlalpan Núm. 4502,

colonia Sección XVI, 14080,

Del. Tlalpan, Ciudad de México.

Teléfono: 555487 1743, ext. 5146

Correo electrónico: drjcvazquez@gmail.com

El autor declara no tener conflictos de intereses. 